\title{
EL DERECHO HUMANO AL ASILO ANTE LA SECURITIZACIÓN DE LA MIGRACIÓN EN MÉXICO
}

\section{The Human Right to Asylum before the SeCuritization of Migration in México}

\author{
Gonzalo Coporo-Quintana* \\ Silvia María Morales-Gómez ${ }^{* *}$ \\ DOI: https://doi.org/10.29043/liminar.vl8i2.780
}

\begin{abstract}
Resumen: En este artículo se realiza un análisis sociojurídico sobre el asilo y la creciente ambigüedad que esta figura ha adquirido en la histórica tradición solidaria de México hacía las personas migrantes con necesidad de protección internacional. Se efectúa un balance geopolítico sobre la política migratoria de Estados Unidos y México, se contrasta con la evolución del asilo en la normatividad jurídica del sistema universal de derechos humanos y del sistema interamericano, y se relaciona con la normatividad mexicana. Con base en ello se concluye que la figura del asilo debe redefinirse en México y debe otorgársele un mayor alcance en el contexto actual de movilidad humana para considerarlo como un derecho humano, tal como ocurre con otras figuras de protección internacional como el refugio y la protección complementaria.
\end{abstract}

Palabras clave: asilo, derechos humanos, seguridad humana, geopolítica.

\begin{abstract}
We undertake a socio-legal analysis regarding the nature of asylum and its growing ambiguity given Mexico's historical tradition of solidarity towards migrants in need of international protection. We discuss the geopolitical situation regarding the migration policy of the United States and Mexico, and contrast it with how asylum has evolved within the legal regulations of the universal human rights and the Inter-American systems, as well as its relationship with Mexican regulations. We conclude that in order for the concept of asylum to be considered a human right, it must be redefined in Mexico to have greater scope in keeping with the current state of human mobility, in line with other concepts of international protection, such as refuge and supplementary protection.
\end{abstract}

Keywords: asylum, human rights, human security, geopolitics.

\footnotetext{
* Gonzalo Coporo Quintana. Doctor en Ciencias Sociales y Humanísticas por el Centro de Estudios Superiores de México y Centroamérica de la Universidad de Ciencias y Artes de Chiapas (CESMECA-UNICACH), México. Profesor del Centro de Estudios para el Desarrollo Municipal y Políticas Públicas de la Universidad Autónoma de Chiapas (CEDESUNACH), México. Temas de especialización: migración, desarrollo y derechos humanos. Correo electrónico: gonzalocporo@yahoo.com.mx. ORCID: https://orcid.org/0000-0002-6230-7767

* Silvia María Morales Gómez. Doctora en Métodos de Solución de Conflictos y Derechos Humanos por la Universidad Juárez Autónoma de
}

Tabasco, México. Profesora delaUniversidad Juárez Autónomade Tabasco, México. Temas de especialización: derechos humanos, mecanismos alternativos de solución de controversias y justicia restaurativa. Correo electrónico: silvia.morales@ujat.mx. ORCID: https://orcid.org/0000-00034973-8121

\footnotetext{
Enviado a dictamen: 14 de agosto de 2019. Aprobación: 2 de marzo de 2020.

Revisiones: 1 .
} 


\section{Introducción}

L a tradición del asilo como parte de la política exterior de México fue reconocida internacionalmente sobre todo por la solidaridad brindada a los españoles perseguidos por la dictadura franquista a finales de los años treinta del siglo pasado, así como por la solidaridad otorgada a los perseguidos políticos de las dictaduras militares de diversos países de América Latina como Guatemala, El Salvador, Nicaragua, Chile o Uruguay entre los años cincuenta y setenta del siglo pasado. Esa tradición que todavía en los ochenta se hizo presente - aunque de manera ambigua - ante el ingreso por la frontera sur de México de miles de desplazados guatemaltecos que huían de su país por la represión del ejército de Guatemala, poco a poco se fue transformando hasta hacerse francamente difusa en el periodo neoliberal en México - desde mediados de los ochenta hasta la primera década del siglo XXI-, esto como consecuencia del viraje tácito en la Doctrina Estrada, ${ }^{1}$ cuya aplicación fue directamente proporcional al otorgamiento del asilo como prerrogativa del Estado, ello aunado a la creciente securitización de la migración a nivel internacional.

Para analizar este viraje en la institución del asilo se retoman los criterios de Giraldo (2002) en referencia a la metodología de la investigación sociojurídica, en la que plantea cuatro etapas: a) el estado del arte, b) la formulación del fin político del sistema normativo correspondiente, c) la problemática social que se pretende superar con el fin político y d) las hipótesis normativas encaminadas a alcanzar el fin.

A partir de lo anterior, en los apartados primero y segundo de este escrito se muestra un estado del arte y se contextualiza la movilidad humana en la frontera sur de México considerando el espacio, el tiempo y la situación geopolítica. Posteriormente, en los apartados tercero, cuarto y quinto se formula el fin político del sistema normativo relacionado con el asilo, el refugio y la protección complementaria. En el penúltimo apartado se presenta la problemática social referente a las caravanas de migrantes de la presente década, y finalmente se propone una hipótesis normativa en las reflexiones finales.

Esta investigación es de tipo documental y en ella se toman como base textos especializados sobre migración en tránsito, sobre estrategia geopolítica de Estados Unidos y sobre normatividad jurídica relacionada con el asilo, el refugio y la protección complementaria.

\section{Migración y geopolítica en la frontera sur}

En las últimas décadas la frontera sur de México adquirió inusitada relevancia hasta alcanzar una dimensión geopolítica importante en el mundo, ello debido a la creciente movilidad humana que circula por esta frontera. Uno de los elementos que han influido en tal situación ha sido la posición geográfica que ocupa para el paso de los migrantes hacia Estados Unidos. La frontera tiene una extensión total de 1149 kilómetros desde Chiapas hasta Quintana Roo, pasando por Tabasco y Campeche, siendo el límite más extenso el que divide a Chiapas de Guatemala con 959 kilómetros (Secretaría de Relaciones Exteriores, 2013), es decir, comparten el 83 por ciento del límite fronterizo total. Es precisamente en esta franja - a la que haremos referencia de aquí en adelante- donde la movilidad humana es mayor, lo cual, cabe mencionar, no es un hecho actual, sino de larga data, dado que hasta 1824 Chiapas y Guatemala eran una misma demarcación político-administrativa.

A partir del establecimiento de los límites fronterizos entre Chiapas y Guatemala en $1824,{ }^{2}$ que fueron redefinidos en 1882, también surgió la migración transfronteriza en el sur de México, es decir, las personas que antes circulaban libremente por la zona de la noche a la mañana se convirtieron en migrantes internacionales y, asimismo, transfronterizos. ${ }^{3}$

Pero además de su específica ubicación geográfica, otro elemento que hizo visible la frontera entre Chiapas y Guatemala fue el desplazamiento forzado de guatemaltecos hacia Chiapas en la década de los ochenta del siglo XX. Se trataba de población que huía de la represión desatada por el ejército de Guatemala 
hacia la guerrilla y la población civil, lo que condujo al desplazamiento forzado de más de 46000 personas; ${ }^{4}$ con el paso del tiempo algunas se establecieron en Chiapas y, posteriormente, otras fueron reubicadas en Campeche y Quintana Roo (Ortiz, 2011; Rodríguez, 2011; Villafuerte, 2011; Castillo y Toussaint, 2015). En este contexto se creó el 22 de julio de 1980 la Comisión Mexicana de Ayuda a Refugiados (COMAR), ${ }^{5}$ que con apoyo del Alto Comisionado de las Naciones Unidas para los Refugiados (ACNUR) buscaría alternativas para la población desplazada.

Durante la década de los noventa la frontera de Chiapas con Guatemala fue escenario de otra oleada de migrantes, ahora diversos, aunque sobre todo se trataba de solicitantes de asilo y refugio que huían, en primer lugar, de la violencia desatada por las pandillas centroamericanas como la Mara Salvatrucha y Barrio 18, pero también huían por causas estructurales como la falta de desarrollo económico o por el ejercicio autoritario y dictatorial del poder de sus gobernantes.

De esa manera, al iniciar el siglo XXI la frontera entre Chiapas y Guatemala era escenario de una intensa movilidad humana: migrantes transfronterizos, migrantes en tránsito, migrantes económicos, migrantes de origen, migrantes de destino, migrantes de retorno, solicitantes de asilo y refugio, así como un creciente número de apátridas.

Aunado a lo anterior, un evento fortuito y externo a México determinante para visibilizar y al mismo tiempo reconfigurar la frontera sur fue el ataque a las torres gemelas del World Trade Center de Nueva York el ll de septiembre de 2001, dado que a partir de entonces la política migratoria de Estados Unidos hizo mayor énfasis en la seguridad nacional y en el control de su frontera con México de una manera más intensa, con especial atención en la migración irregular, ${ }^{6}$ a la vez que exigió a México el mismo control migratorio en sus dos fronteras.

A partir de ese momento los inmigrantes de cualquier modalidad que arribaban a México, pero particularmente los solicitantes de asilo y refugio, ya no tendrían el recibimiento generoso de otros tiempos porque se impulsaron distintos planes y programas migratorios entre los que se encuentran: el Plan Sur en 2001, el Plan Puebla Panamá en 2001 ${ }^{7}$ —Proyecto Mesoamericano a partir de 2008-, la Iniciativa Mérida en $2008^{8}$ y el Programa Frontera Sur entre 2014 y 2016. Si bien cada uno de estos planes respondió a estrategias específicas, lo común en todos ellos fue, y sigue siendo, la contención de la migración a través del reforzamiento de la seguridad fronteriza con recursos otorgados por Estados Unidos. ${ }^{9}$

De esta manera, la importancia de la frontera sur en las últimas décadas ha sido producto de factores internos y externos a México, primando en este último caso los intereses políticos, económicos, geográficos y de seguridad nacional del país hegemónico en el continente, Estados Unidos, que avasalla los mecanismos de control de la migración en México y también de los países del norte de Centroamérica — Guatemala, El Salvador y Honduras-.

\section{Securitización de la migración como estrategia geopolítica}

La seguridad en el continente americano ha estado ligada históricamente a los intereses de Estados Unidos, lo cual se ha expresado desde la Doctrina Monroe en 1823, hasta la Doctrina del Destino Manifiesto a partir de $1840^{10}$ y la política del Gran Garrote de Roosevelt a principios del siglo XX, programas mediante los cuales Estados Unidos se ha atribuido el derecho de intervenir política o militarmente en los países del continente bajo el argumento de defender los intereses de sus ciudadanos. ${ }^{11}$

Si bien la estrategia geopolítica mundial de Estados Unidos hasta finales del siglo XX ha sido diversa, según se han producido los reacomodos políticos en el mundo, ${ }^{12}$ un nuevo punto histórico de inflexión se definió, como hemos señalado previamente, el 11 de septiembre de 2001 tras los eventos de Nueva York, a partir de los cuales el país incrementó las restricciones a la movilidad humana de todo tipo, lo que afectó en primer lugar a los migrantes mexicanos, y en segundo lugar a los migrantes en tránsito - continentales o extracontinentales- que cruzan por México. 
De esta manera, la migración hacia Estados Unidos empezó a tratarse como un tema de seguridad nacional ${ }^{13}$ y con ello la política migratoria se "securitizó", proceso que, según Joao Guia, se define de la siguiente manera:

El proceso de securitización del espacio de la inmigración produce que el migrante sea percibido como una amenaza a la "identidad"; se lo representa como un rival de los autóctonos y no como alguien que, potencialmente, puede formar parte de la sociedad. En este contexto, el individuo deja de ser castigado por la comisión de un delito y comienza a ser criminalizado porque forma parte del grupo de los peligrosos (Joao Guia, 2012:595).

Bajo esta estrategia de securitización de la migración México se convirtió, en los hechos, en un país frontera, porque en sí mismo todo su territorio es una frontera, como bien han dicho varios autores, entre ellos Torre y Yee:

[...] los migrantes centroamericanos que cruzan el país con destino a Estados Unidos están continuamente expuestos a ser detenidos [en cualquier lugar de México] y expulsados de diversas formas contempladas en la legislación mexicana; esta implementación de la política migratoria en el país ha sido denominada por varios autores como frontera vertical (Torre y Yee, 2018:88).

\section{El asilo en el contexto de la securitización de la migración}

En México la institución del asilo ${ }^{14}$ como instrumento de protección internacional ha ido cambiando según la orientación política de los gobiernos en turno, de tal manera que desde el presidente Lázaro Cárdenas, hasta el periodo de securitización de la migración que corresponde a los gobiernos neoliberales (1980-2018), se pueden distinguir tres visiones distintas en torno a esta institución que se relacionan a continuación.

El periodo de Cárdenas fue reconocido a nivel mundial porque se otorgó asilo a los españoles perseguidos políticos por la dictadura de Francisco Franco. Hay que reconocer que en ese proceso existió una posición elitista, y en cierto sentido selectiva, para el otorgamiento del asilo, en tanto que a personas de otras nacionalidades no se les brindó el mismo trato. ${ }^{15}$

Desde Lázaro Cárdenas hasta la década de los ochenta ${ }^{16}$ la institución del asilo se mantuvo más o menos sin cambios, ${ }^{17}$ pero posteriormente empezó a mostrar limitaciones porque bajo ese esquema no se podía atender a los desplazados de Guatemala que llegaban por la frontera sur de México, por lo que el gobierno, con el apoyo del ACNUR, creó la COMAR y estableció mecanismos para regularizar su estancia en nuestro país. En ese proceso el gobierno mexicano también efectuó cierto nivel de selectividad para otorgar asilo o refugio, aunque la composición socioeconómica y étnica de los desplazados era distinta a la de los asilados de otros tiempos.

El limbo jurídico entre asilo y refugio quedó en evidencia al no poder otorgarles el reconocimiento de asilados a los guatemaltecos, por ello mediante la COMAR se creó la figura de refugiado, la cual fue reconocida hasta el año 2000, cuando México firmó el pacto de adhesión a la Convención sobre el Estatuto de los Refugiados de $1951^{18}$ y el Protocolo sobre el Estatuto de los Refugiados de 1967 de la Organización de Naciones Unidas (ONU). ${ }^{19}$ Con esta adhesión se crearon las figuras de refugio y de refugiado, en cambio la figura del asilo se mantendría tal cual en su versión mexicana. Por ello consideramos que, si bien la adhesión a la Convención y al Protocolo sobre el Estatuto de Refugiados permitía atender los desplazamientos forzados e incluso las corrientes migratorias en general, también hacía difusa la institución del asilo en México, en tanto que esta se constituyó, con sus particularidades, mediante el conjunto de convenciones y tratados propios de la tradición latinoamericana sobre asilo, y no mediante la Convención sobre los Refugiados de la ONU.

En la misma década de los años 2000, y con dos gobiernos de derecha en México —el de Vicente Fox (2000-2006) y el Felipe Calderón (2006-2012) la política exterior de este país dio un giro en las 
relaciones internacionales con otros Estados, lo cual se sustentó jurídicamente en las modificaciones al artículo 89 constitucional y en la transformación de la Doctrina Estrada ${ }^{20}$ lo que en la práctica se tradujo en un trato grosero y poco diplomático hacia gobiernos de América Latina con los que México había tenido afinidad política como Cuba, Venezuela y Nicaragua, entre otros, a los cuales ahora criticaba arguyendo falta de democracia y violaciones a los derechos humanos.

La convergencia de los gobiernos de derecha en México, ${ }^{21}$ junto con los eventos del ll de septiembre de 2001 en Estados Unidos, abonó a la securitización de la migración en México, principalmente por el apoyo de los gobiernos mexicanos mencionados a diversos programas destinados a detener el flujo migratorio sur-norte, como el Plan Puebla Panamá (2001), la Iniciativa Mérida (2008) y el Programa Frontera Sur (2014-2016)

De acuerdo con lo anterior, es entendible que en el periodo neoliberal la tradición del asilo en México se volviera difusa y sin relevancia en el ámbito internacional, aunque es de reconocer la importancia que ganó la figura de refugio, lo cual se produjo en el contexto de las reformas constitucionales del año 2011.

\section{Marco normativo del asilo como institución de protección internacional}

La Corte Interamericana de Derechos Humanos considera el asilo como: "la figura rectora que recoge la totalidad de las instituciones vinculadas a la protección internacional de las personas forzadas a huir de su país de nacionalidad o residencia habitual" (Corte IDH, 2018a:párr. 65).22 Pasó de ser una institución humanitaria o religiosa a erigirse en una institución jurídica reconocida en el derecho internacional, cuyo fin primordial es preservar la vida, la seguridad, la libertad o la integridad de la persona. Al respecto, Martínez menciona que: "Cuando se habla del asilo como una institución se pone el énfasis en la protección que brinda una entidad (Estado) vista como una práctica, uso o actuación unida por cierta estabilidad y homogeneidad que refleja la conducta de los miembros de una colectividad (comunidad internacional)" (Martínez, 2012:25).

\section{Asilo, refugio y protección complementaria}

En este apartado se analizan los aspectos jurídicos que caracterizan las distintas formas de protección internacional previstas en el artículo ll párrafo segundo de la Constitución Política de los Estados Unidos Mexicanos, donde se contemplan el asilo y el refugio, y de manera adicional se hace referencia a la protección complementaria, ya que dichas figuras conforman la protección humanitaria ante la persecución.

\section{Asilo}

El asilo territorial se otorga en el territorio del Estado en el que se solicita, y es la protección que un Estado brinda en su espacio a las personas nacionales o residentes habituales de otro Estado en donde son perseguidas por motivos políticos, por sus creencias, opiniones o filiación política, o por actos que puedan ser considerados como delitos políticos o comunes conexos (Corte IDH, 2018a:párr. 67).

El asilo diplomático tiene características particulares al estar sujeto a las convenciones de carácter interestatal que lo regulan y a lo dispuesto en las legislaciones internas. De esta manera, la Corte IDH ha establecido que el asilo diplomático no se encuentra protegido bajo el artículo 22.7 de la Convención Americana sobre Derechos Humanos o el artículo XXVIII de la Declaración Americana de los Derechos y Deberes del Hombre (Corte IDH, 2018a:64).

En el sistema interamericano, la Declaración Americana de los Derechos y Deberes del Hombre ${ }^{23}$ y la Convención Americana sobre Derechos Humanos, ${ }^{24}$ de acuerdo con lo establecido en sus artículos XXVII y 22.7 respectivamente, ${ }^{25}$ fueron el sustento para que la Corte IDH emitiera la opinión consultiva OC-25/2018, donde se expresa lo siguiente: "el derecho a buscar y recibir asilo en el marco del sistema interamericano se encuentra configurado como un derecho humano a recibir y buscar protección internacional en territorio 
extranjero, incluyendo con esta expresión el estatuto de refugiado" (Corte IDH, 2018a:64). Con ello se supera la noción de considerar el asilo como una prerrogativa del Estado bajo las diversas convenciones americanas.

La Declaración Universal de los Derechos Humanos (1948) reconoce en su artículo $14^{26}$ el asilo como un derecho de las personas; señala el derecho a buscar asilo, pero no indica el "derecho de recibir asilo".

El derecho a buscar implica el derecho a solicitar o pedir el asilo en el territorio de un Estado sin discriminación alguna, lo que conlleva una obligación estatal de acuerdo con el objeto y el fin de la norma; además se explicita la premisa fundamental de facilitar el acceso a la institución del asilo a la persona solicitante, que asegure una correcta evaluación por parte de las autoridades nacionales de las solicitudes y del riesgo que pueda sufrir la persona en caso de devolución, sin formalismos rígidos y atendiendo a las peticiones de manera pronta para hacer eficaz el núcleo duro del derecho humano al asilo y evitar las prácticas de expulsión o devolución de quienes solicitan asilo.

Por otra parte, al hablar del derecho a recibir asilo se alude a la obligación del Estado a no sancionar a la persona extranjera que busca protección por el ingreso o permanencia irregular en su territorio, en cumplimiento a las disposiciones establecidas en los artículos 31 de la Convención sobre de Refugiados de 1951 y 5 de la Convención sobre Asilo Territorial de 1954, respectivamente.

Si bien los Estados tienen la facultad de controlar y regular el ingreso y la permanencia de personas extranjeras en su territorio, lo que constituye un fin legítimo, en los hechos "la penalización de la entrada irregular en un país supera el interés legítimo de los Estados en controlar y regular la inmigración irregular y puede dar lugar a detenciones innecesarias" (ONU, 2008:párr. 53), ya que la detención de personas por incumplimiento de las leyes migratorias nunca debe ser con fines punitivos. En tal sentido, el artículo 31 de la Convención sobre el Estatuto de los Refugiados de 1951 garantiza la no imposición de sanciones penales por causa de entrada o presencia ilegal.

\section{Refugio}

En el sistema universal dosinstrumentosinternacionales fortalecen la protección específica de las personas que se ven forzadas a abandonar sus hogares por una ruptura con su país de origen: la Convención sobre el Estatuto de los Refugiados de 1951 y el Protocolo sobre el Estatuto del Refugiado de 1967, además de la Declaración de Cartagena sobre los Refugiados de 1984. ${ }^{27}$ Estos tres instrumentos constituyen la base del régimen internacional de protección a los refugiados y son reconocidos como los de mayor relevancia universal en cuanto a la protección de las personas que huyen por persecución y solicitan la protección a un Estado distinto al de su origen.

En México, la Ley sobre Refugiados, Protección Complementaria y Asilo Político ${ }^{28}$ y su reglamento reconocen el refugio como la protección que el Estado otorga al extranjero cuando se encuentre en territorio nacional y esté en peligro su vida, su libertad o su seguridad, en los supuestos siguientes:

1. debido a fundados temores de ser perseguido por motivos de raza, religión, nacionalidad, género, pertenencia a determinado grupo social u opiniones políticas;

2. por violencia generalizada, agresión extranjera, conflictos internos, violación masiva de los derechos humanos $u$ otras circunstancias que hayan perturbado gravemente el orden público;

3. debido a circunstancias que hayan surgido en su país de origen o como resultado de actividades realizadas, durante su estancia en territorio nacional, de manera que tenga fundados temores de ser perseguido por motivos de raza, religión, nacionalidad, género, pertenencia a determinado grupo social u opiniones políticas, o su vida, seguridad o libertad pudieran ser amenazadas por violencia generalizada, agresión extranjera, conflictos internos, violación masiva de los derechos humanos $u$ otras circunstancias que hayan perturbado gravemente el orden público. 
Este último inciso retoma la conclusión tercera de la Declaración de Cartagena. Si se toma en cuenta que México suscribió la Convención de 1951, esta definición formó parte del orden jurídico mucho antes de encontrarse establecida en la ley. La Declaración de Cartagena amplió la definición de refugiado; esta definición fue adoptada en México en junio de 1990 a través de una adicción a la fracción VI del artículo 42 de la Ley General de Población, mediante la cual se reconoció la figura de refugiado como una condición de estancia temporal en este país.

\section{Protección complementaria}

La protección complementaria prevista en el artículo 27 de la Ley sobre Refugiados, Protección Complementaria y Asilo Político hace referencia a la protección que el Estado otorga a la persona extranjera que no reúne los supuestos para obtener la condición de refugiada o asilada, y que requiere protección para no ser devuelta al territorio de otro país donde su vida peligre, o que por razones fundadas se considere que pueda ser sometida a torturas u otros tratos o penas crueles, inhumanos o degradantes.

México ha integrado en el reconocimiento de los refugiados los criterios establecidos en la conclusión núm. 103 del Comité Ejecutivo del Programa del Alto Comisionado de las Naciones Unidas para los Refugiados (ACNUR, 2005), que recomienda el uso de formas complementarias de protección para particulares necesitados de protección internacional cuando no reúnan las condiciones para ser reconocidos como refugiados en los instrumentos internacionales. La conclusión menciona que los Estados podrán optar por autorizar una estancia prolongada por razones humanitarias o prácticas, y reconoce que esos casos deben distinguirse claramente de aquellos en que existen necesidades de protección internacional.

Finalmente, la Corte IDH ha considerado que la protección complementaria es una manera a través de la cual el Estado reconoce la situación de la persona, identifica su riesgo y tiene conocimiento de sus necesidades (Corte IDH, 2018b:párr. 238).

\section{El asilo y las caravanas migrantes}

De acuerdo con algunos autores como Durand (2018), las caravanas iniciadas en 2018 expresan una nueva estrategia de movilidad sur-norte para transitar por México de manera "segura", lo cual es acertado porque la migración transfronteriza y la migración de tránsito por la frontera sur de México han sido constantes desde hace algunos años, solo eran menos visibles.

Las caravanas actuales se caracterizan por la heterogeneidad de sus integrantes. En cuanto a las características de edad, participan en ellas personas de todas las edades, incluidos niñas, niños y adolescentes ${ }^{29}$ - acompañados o no-, que por ese solo hecho deben ser beneficiarios de la protección internacional: asilo, refugio o protección complementaria.

Aunque acceder al procedimiento para solicitar protección internacional tiene sus vicisitudes, de hecho poco se conoce que en los lineamientos para atender solicitudes de asilo y refugio de la Secretaría de Relaciones Exteriores (2016) el asilo no es considerado como un derecho humano; ello evidentemente entra en contradicción con la Constitución mexicana y con el derecho internacional de los derechos humanos.

Algunas de las fallas del procedimiento para otorgar asilo son mencionadas en un reporte de Human Rights Watch (2016) donde se hace alusión a los criterios seguidos por el Instituto Nacional de Migración en México:

Cuando le preguntamos a la funcionaria del INM que dirige el departamento encargado de la expedición de estas visas [asilo] qué criterios sigue su personal, nos dijo que el INM simplemente comprueba si se han cumplido los requisitos legales. Aquellos que presentan su solicitud basándose en que fueron víctimas de delitos graves están obligados a presentar una denuncia ante la policía con el fin de recibir una visa humanitaria, aseguró la directora. Ante la pregunta de qué delitos califican para recibir una visa humanitaria, ella respondió que el INM se basa en la oficina del fiscal para hacer esa determinación (Human Rights Watch, 2016:82). 
Expresiones de esta naturaleza muestran que no hay criterios claros para otorgar o denegar el asilo o, en su caso, el refugio. La aplicación de la política de asilo por parte de los funcionarios tiene un efecto negativo en la protección de los derechos humanos de los grupos vulnerables, como en el caso de los niños, niñas y adolescentes, cuya migración se acentuó entre los años 2011 y $2015 .^{30}$ Pero también vulnera los derechos de aquellos migrantes que han sido objeto de violencia en sus países de origen y que son devueltos.

El 6 de diciembre de 2018 la CNDH emitió un informe titulado Participación en la Audiencia Regional: situación de derechos humanos de las personas que integran la Caravana de Migrantes ante la Comisión Interamericana de Derechos Humanos en el que advierte sobre los obstáculos en el ejercicio de su trabajo cotidiano:

En la etapa de "recorridos cortos", especialmente en las entidades federativas de Chiapas y Oaxaca en que se ofreció el programa "Estás en tu casa", se vinculó la solicitud del ejercicio de este derecho únicamente ante el INM, siendo que por ley puede hacerse directamente ante la COMAR o ante cualquier otra autoridad, estando obligada esta última a referirlo a la COMAR (CNDH, 2018:12).

En el informe de la CNDH también se reconoce la situación crítica de la COMAR debido a la falta de infraestructura, pero también al rezago de los expedientes que se encuentran en trámite en esa institución.

\section{Reflexiones finales}

El viraje en la concepción del asilo fue modificándose paulatinamente por la política exterior de los gobiernos neoliberales en México, posición que fue afianzándose al amparo de la estrategia geopolítica de securitización de la migración de Estados Unidos.

Ahora bien, la migración en caravanas por la frontera sur de México permite nuevamente voltear la mirada hacia esta figura de protección internacional, cuyo papel en la actualidad es francamente difuso y sin relevancia en la política exterior.
Por lo anterior, es necesario considerar que las reformas realizadas en el año 2011 a la Constitución mexicana, que otorgaron rango constitucional a los tratados y convenios que México ha firmado en materia de derechos humanos, así como el pronunciamiento en 2013 de la Suprema Corte de Justicia de la Nación para que los derechos humanos contemplados en los tratados internacionales adquieran la misma jerarquía constitucional, además de la opinión consultiva OC-25/2018 de la Corte IDH (2018a), representan los fundamentos para que el asilo en México sea considerado como un derecho humano explícito en los lineamientos de la Secretaría de Relaciones Exteriores.

Asimismo, en el contexto actual de movilidad humana sur-norte, y ante la estrategia geopolítica estadounidense de securitización de la migración, es indudable que el asilo, tanto diplomático como territorial, cobrará relevancia en México, por lo que debe darse una nueva redefinición de esta figura de protección internacional y evaluar su peso específico con las otras figuras de protección como el refugio y la protección complementaria.

Finalmente, es relevante mencionar que debe ser el enfoque de seguridad humana, y no el de seguridad nacional, el que tiene que prevalecer en el trato a los migrantes en tránsito independientemente de su condición migratoria.

\section{Notas}

${ }^{1}$ La doctrina Estrada, creada en la década de los treinta del siglo pasado por Genaro Estrada, secretario de Relaciones Exteriores en el gobierno del presidente Pascual Ortiz Rubio, además de enarbolar el principio de no intervención y la autodeterminación de los pueblos proponía, hasta antes de la reforma al artículo 89 de 2007, que México no podía pronunciarse para otorgar el reconocimiento a los gobiernos extranjeros, sino que debía limitarse a mantener o retirar, cuando lo considerara prudente, a sus agentes diplomáticos y continuar aceptando a los agentes diplomáticos de los países con los que México tenga acuerdos, pero 
sin pronunciarse a favor de su gobierno (Péreznieto, 2002).

${ }^{2}$ Los límites más o menos formales se establecieron en 1882 mediante el tratado de límites firmado entre México y Guatemala.

${ }^{3}$ La construcción de ciudadanía e identidad nacional mexicana en esta frontera fue un proceso complejo lleno de conflictos sociojurídicos, sobre todo vinculados con los trabajadores agrícolas de Guatemala (Nolan, 2018)

${ }^{4}$ La cifra de refugiados pudo ser mayor si se consideran los desplazados no reconocidos como refugiados por la Comisión Mexicana de Apoyo a los Refugiados (COMAR).

${ }^{5}$ Hasta ese año la Ley General de Población de México no contemplaba la figura de refugiado bajo alguna norma específica, por lo que con la creación de la COMAR se buscó subsanar ese vacío jurídico al otorgar visas temporales. Pero no fue sino hasta 1990 cuando se publicó en el Diario Oficial de la Federación una adicción a la fracción VI del artículo 42 de la entonces Ley General de Población en la que se reconocía la figura de refugiado.

${ }^{6}$ Esto se reflejó en diversas leyes antiinmigrantes en: Arizona SB1070, Utah HB497, Indiana SB590, Georgia HB87, Alabama HB56 y Carolina del Sur S20, entre otras. Lo anterior se produjo a la par del reforzamiento de la seguridad fronteriza. Casi una década antes del año 2001, en 1990, Estados Unidos empezó a construir en San Diego el primer muro fronterizo.

7 Esta estrategia tenía como objetivo el desarrollo de las entidades del sur y sureste de México, pero al mismo tiempo la incorporación a varios países de Centroamérica, entre ellos, los países del norte de esta región: Guatemala, El Salvador y Honduras.

${ }^{8}$ Para la Comisión Interamericana de Derechos Humanos el Proyecto Mérida, como también se conoce, privilegia en todo momento una visión de seguridad nacional.

${ }^{9}$ En septiembre de 2018, de manera más abierta, es decir, sin ningún plan de por medio, se anunció que el gobierno de Donald Trump: "contempla el pago de 20 millones de dólares al gobierno mexicano para ayudarlo a deportar a inmigrantes indocumentados procedentes de América Central" (Langner, 2018), lo anterior con el afán de convencer a México para que acepte el estatus de tercer país seguro.

${ }^{10}$ De acuerdo con Rioja: "la geoestrategia estadounidense se enfocó en garantizar la seguridad y la paz hemisférica, ligada a la Doctrina Monroe, mientras que por parte del Destino Manifiesto, se planteó la necesidad de la expansión territorial y anexionista para asegurar su predominio en el continente americano, cuya influencia se hace manifiesta en la actualidad mediante la Doctrina de Seguridad Hemisférica" (Rioja, 2015:35).

${ }^{11}$ Nos referimos a lo que podría llamarse "geopolítica latinoamericana", sin perder de vista que el origen del concepto surgió en Europa, y de manera específica en Alemania. Entre los principales teóricos alemanes de este concepto se encuentra Karl Haushofer, quien al parecer se deslindó de la geopolítica nazi como instrumento de dominación.

${ }^{12}$ A partir de 1947 la doctrina de seguridad nacional estadounidense se enfocó en detener el avance del comunismo, y en América Latina esto se reflejaría en el apoyo brindado a las dictaduras militares y en el combate a la guerrilla.

${ }^{13}$ La seguridad nacional puede ser entendida como: "el conjunto de políticas, estrategias, normas, instituciones y acciones que tienden a la armonización plena de los elementos constitutivos del Estado, protegiéndolos y salvaguardándolos de actos o situaciones de cualquier naturaleza, internos o externos que perjudiquen o afecten de alguna manera su integridad o su óptimo desempeño y aprovechamiento en el impulso del proceso de desarrollo y el progreso del país en todos los órdenes (Rioja, 2015:31)

${ }^{14} \mathrm{El}$ asilo se puede clasificar en asilo diplomático y asilo territorial. Por el uso histórico que México ha hecho de esta institución, se ha identificado el asilo como asilo diplomático o asilo político.

${ }^{15}$ Ver Serano Migallón (1998).

${ }^{16}$ La década de los ochenta marcó el inicio del periodo neoliberal en México, cuando el proyecto de nación se orientó hacia la expansión de la economía con Estados Unidos y Canadá. Ello también implicó un reacomodo económico y político con los países latinoamericanos y del Caribe. 
${ }^{17}$ La normatividad relacionada con el estaría acorde con la tradición latinoamericana que se configuró en el continente a partir de 1889.

${ }^{18}$ Adoptada en Ginebra, Suiza, el 28 de julio de 1951 por la Conferencia de Plenipotenciarios sobre el Estatuto de los Refugiados y de los Apátridas.

${ }^{19}$ Firmado en Nueva York el 31 de enero de 1967, con entrada en vigor el 4 de octubre de 1967. México se adhirió a este protocolo el 7 de junio de 2000.

${ }^{20}$ Las dos reformas al artículo 89 constitucional se realizaron en 2007 y 2011. En esta última se agregó el concepto de derechos humanos. En cuanto a la Doctrina Estrada, ver nota 1.

${ }^{21}$ El gobierno de Enrique Peña Nieto también puede ser considerado de derecha a pesar que su partido, el Partido Revolucionario Institucional, se considera como un partido de centro. Sin embargo, en la práctica mantuvo en cuanto a relaciones internacionales la misma posición que los gobiernos panistas.

${ }^{22}$ El 30 de mayo de 2018 la Corte IDH emitió la opinión consultiva OC-25/18, denominada "La institución del asilo y su reconocimiento como derecho humano en el sistema interamericano de protección”, en la cual desentraña el sentido, propósito y razón de las normas internacionales sobre derechos humanos, a partir de una interpretación judicial sobre disposiciones de la Convención o de otros tratados relacionados con la protección de los derechos humanos en el Sistema Interamericano, con el propósito de coadyuvar con los Estados al cumplimiento de sus compromisos internacionales (Corte IDH, 2018a).

${ }^{23}$ Aprobada en la Novena Conferencia Internacional Americana, Bogotá, 1948.

${ }^{24}$ Adoptada en San José, Costa Rica, el 22 de noviembre de 1969. México se adhirió el 24 de marzo de 1981.

${ }^{25}$ El artículo XXVII de la Declaración Americana de los Derechos y Deberes del Hombre reza así: "Derecho de asilo. Toda persona tiene el derecho de buscar y recibir asilo en territorio extranjero, en caso de persecución que no sea motivada por delitos de derecho común y de acuerdo con la legislación de cada país y con los convenios internacionales". El artículo 22 de la Convención Americana sobre Derechos Humanos menciona lo siguiente: "Derecho de Circulación y de Residencia 7. Toda persona tiene el derecho de buscar y recibir asilo en territorio extranjero en caso de persecución por delitos políticos o comunes conexos con los políticos y de acuerdo con la legislación de cada Estado y los convenios internacionales".

${ }^{26}$ Artículo 14. 1) En caso de persecución, toda persona tiene derecho a buscar asilo, y a disfrutar de él, en cualquier país. 2) Este derecho no podrá ser invocado contra una acción judicial realmente originada por delitos comunes o por actos opuestos a los propósitos y principios de las Naciones Unidas.

27 Adoptada durante el Coloquio sobre la Protección Internacional de los Refugiados en América Central, México y Panamá Problemas Jurídicos y Humanitarios, celebrado en Cartagena, Colombia, del 19 al 22 de noviembre de 1984.

${ }^{28}$ La última reforma a la Ley sobre Refugiados, Protección Complementaria y Asilo Político se publicó en el Diario Oficial de la Federación el 30 de octubre de 2014.

29 Las medidas cautelares de la caravana migrante que ingresó a México en octubre de 2018 (Voces Mesoamericanas, 2018), solicitada por diversas organizaciones defensoras de los derechos humanos de los migrantes, es representativa de la existencia de dichos grupos vulnerables difuminados en la Caravana. También es representativo de lo anterior, el artículo "Caravana de contrastes" de Jorge Durand (2018) sobre la heterogeneidad y vulnerabilidad de estos grupos.

${ }^{30}$ Obviamente sin que hasta el momento la migración de los niños, niñas y adolescentes haya dejado de fluir, aunque no como en ese periodo.

\section{Referencias}

ACNUR (Alto Comisionado de Naciones Unidas para los Refugiados) (2005). Informe del 56º período de sesiones del Comité Ejecutivo del Programa del Alto Comisionado B. Conclusión sobre la disposición sobre protección internacional, en particular mediante formas complementarias de protección. A/AC.96/1021 7 de octubre. Disponible en: https://www.acnur.org/ fileadmin/Documentos/BDL/2005/3862.pdf 
Castillo, Manuel Ángel y Mónica Toussaint (2015). "La frontera sur de México: orígenes y desarrollo de la migración centroamericana". En Cuadernos Inter.c.a.mbio sobre Centroamérica y el Caribe, 12(2), 59-87. Disponible en: https://dialnet.unirioja.es/descarga/ articulo/5249224.pdf

CNDH (Comisión Nacional de Derechos Humanos) (2018). Participación en la Audiencia Regional: situación de derechos humanos de las personas que integran la Caravana de Migrantes ante la Comisión Interamericana de Derechos Humanos. México: CNDH. Disponibleen: http://www. cndh.org.mx/sites/all/doc/Informes/Especiales/INFCNDH-CIDH-CARAVANA.pdf

Corte IDH (Corte Interamericana de Derechos Humanos) (2018a). Opinión consultiva OC-25/18. La institución del asilo y su reconocimiento como derecho humano en el sistema interamericano de protección solicitada por la República del Ecuador. San José. Disponible en: http:// www.corteidh.or.cr/docs/opiniones/seriea_25_esp.pdf

Corte IDH (Corte Interamericana de Derechos Humanos) (2018b). Opinión consultiva OC-21/14. Derechos y garantías de niñas y niños en el contexto de la migración y/o en necesidad de protección internacional. solicitada por la República argentina, la República federativa de Brasil, la República del Paraguay y la República del Uruguay. Disponible en: http://www.corteidh.or.cr/index.php/observaciones

Durand, Jorge (2018). "Caravana de contrastes". En La Jornada, 25 de noviembre. Disponible en: https:// www.jornada.com.mx/2018/11/25/opinion/018alpol

Giraldo Ángel, Jaime (2002). Metodología y técnica de la investigación sociojurídica. Bogotá: Facultad de Derecho y Ciencias Políticas-Universidad de Ibagué.

Human Rights Watch (2016). Puertas cerradas. El fracaso de México en la protección de niños refugiados y migrantes de América Central. S/l: Human Rights Watch. Disponible en: https:/www.hrw.org/sites/default/files/report pdf/mexico0316_spweb.pdf

Joao Guia, María (2012). “Crimigración, securitización y la criminalización de los migrantes en el sistema penal". En Anuario da Facultade de Dereito da Universidade da Coruña, 16, 591-613. Disponible en: https://ruc.udc. es/dspace/bitstream/handle/2183/12016/AD_16_2012_
art_26.pdf;jsessionid=E4679E9lFF16714CF967EE01EE 28ED84? sequence $=1$

Langner, Ana (2018) . "Trump ofrece 20 millones de dólares a México para deportar migrantes de Centroamérica”. En La Jornada, 13 de septiembre. Disponible en: http:// www.jornada.com.mx/sin-fronteras/2018/09/13/ gobierno-de-trump-planea-pagar-a-mexico-paradeportar-inmigrantes-de-centroamerica-3957.html

Martínez Monge, Federico (2012). "El asilo como fundamento en la protección de los refugiados". En Víctor Abramovich et al., Protección internacional de refugiados en el sur de Sudamérica. Remedios de Escalada, Argentina: Universidad Nacional de Lanús. Disponible en: http://biblioteca.clacso.edu.ar/ Argentina/cdhunla/20171030045033/pdf_1543.pdf

Nolan Ferrell, Catherine A. (2018). La construcción de ciudadanía. Los trabajadores transnacionales y la revolución en la frontera México-Guatemala, 1880-1950. San Cristóbal de Las Casas, Chiapas: CIMSUR-UNAM.

Ortiz Monasterio, Luis (2011). "Refugiados guatemaltecos: lecciones y aprendizajes”. En Katya Somohano y Pablo Yankelevich (coords.), El refugio en México. Entre la historia y los desafíos contemporáneos. México: COMAR/SEGOB.

Péreznieto Castro, Leonel (2002). "La doctrina Estrada, una nota para su relectura”. En RI, 89, mayo-agosto, 121-126. Disponible en: http://www.revistas.unam. mx/index.php/rri/article/download/66413/58297

Rioja, Leonardo (2015). "El imaginario de la seguridad en la frontera sur de México a principios del siglo XXI". En Península, 10(1), enero-junio, 29-47. Disponible en: https://www.sciencedirect.com/science/article/pii/ S1870576615000033

Rodríguez Chávez, Ernesto (2011). "Asilo, refugio y otras formas de protección humanitaria en el México del siglo XXI". En Katya Somohano y Pablo Yankelevich (coords.), El refugio en México. Entre la historiay los desafíos contemporáneos. México: COMAR/ SEGOB.

Secretaría de Relaciones Exteriores (2013). Diagnóstico general de la frontera entre México y Guatemala. 8 de mayo de 2013. México: Secretaría de Relaciones Exteriores. Disponible en: http://www.senado.gob.mx/comisiones/ relext_orgint/eventos/docs/fronterasur_ponencia.pdf 
Secretaría de Relaciones Exteriores (2016). Lineamientos para atender solicitudes de asilo y refugio. México: Secretaría de Relaciones Exteriores. Disponible en: https:/extranet.sre.gob.mx/images/stories/asilo/ asilo2016.pdf

Serrano Migallón, Fernando. (1998). El asilo político en México. Ciudad de México: Porrúa.

Torre Cantalapiedra, Eduardo y José Carlos Yee Quintero (2018). México iuna frontera vertical? Políticas de control del tránsito migratorio irregular y sus resultados, 2007-2016. En LiminaR. Estudios Sociales y Humanísticos, 16(2), 87-104. Disponible en: http://liminar.cesmeca.mx/index.php/ rl/article/view/599
Villafuerte Solís, Daniel (2011). "Políticas de seguridad y migración transnacional en la frontera sur de México". En Daniel Villafuerte Solís y María del Carmen García Aguilar (coords.), Migración. seguridad, violencia y derechos humanos. Lecturas desde el sur. México: Miguel Ángel Porrúa, pp. 167-207.

Voces Mesoamericanas. Acción con pueblos migrantes (2018). Medidas cautelares para caravana migrante proveniente de Centro América en crisis humanitaria. México. Voces Mesoamericanas. Disponible en: http://vocesmesoamericanas.org/noticias/medidascautelares-para-caravana-migrante-proveniente-decentro-america-en-crisis-humanitaria-mexico/ 